\title{
Different Cultures and Learning Styles Matter in a Canadian University with Middle Eastern students
}

\author{
Tracey Lemke-Westcott, Brad Johnson \\ University of Calgary Qatar
}

\begin{abstract}
The research project at the University of Calgary in Qatar (UCQ) focused on the learning style differences and cultural differences of faculty from Canada teaching in Qatar and students from the Middle-East (ME). Such transnational education opportunities have increased abroad as branch campuses or as inclusions of foreign students on home campuses, and involve unique challenges arising from differences in academic expectations, teaching and learning styles, and cultural settings [3]. Therefore, this project used several international learning style assessments and interviews to uncover differences between faculty and students which may impede or aid pedagogical effectiveness and academic success.
\end{abstract}

\section{Introduction}

According to Miller-Idriss and Hanauer [3], there are about 100 transnational educational institutions overseas with nearly $60 \%$ of these in the MiddleEast. The vast majority of the educators come from the home campus or from a similar cultural background [1]. By contrast, most students in these branch campuses in the Middle-East, for example, are locals of their country or residents from ME regions nearby. Their cultural differences are reinforced in their background education system, and this plays a major role in developing learning styles and orientations [19].

Therefore, the differences in learning styles and orientations found between faculty from Canada and students from the ME in this particular research project at the University of Calgary in Qatar may be primarily indicative of cultural differences. The effect in the transnational education institution may be an initial misalignment of teaching methods and learning styles as well as education goals or expectations. The faculty or students may adapt more readily if they gain an awareness of cultural differences and learning styles to more effectively bridge this education gap.

\section{Cultural Differences}

Culture underlies and influences education, values and learning styles. Religion, socioeconomic status and region are highly influential forms of culture affecting transmitted norms, values, beliefs and behaviors, along with core cultural influences such as ethnicity or nationality [2].

Learning styles may differ among individuals and even across cultures [2]. Many university students in Qatar are culturally from the Middle-East, and are educated by faculty from North American or other international institutions. Identification of students' specific learning styles and preferences may lead to the development of more effective teaching methods to eliminate learning barriers and foster student strengths in the educational setting [9].

This research study focused on a transnational institution, the Canadian University of Calgary in Qatar, consisting of faculty from Western Canada and students from the Middle-East, where cultural differences need to be considered. According to international global cultural studies, Western Canada is classified in the Anglo cultural cluster, and Qatar is classified in the Middle-East cultural cluster [10]. Each cluster has unique characteristics. For example, Anglo countries are high in performance orientation, and $\mathrm{ME}$ countries are mid-range in valuing performance. So results, competition, productivity and efficiency are valued more highly in Anglo countries than in the ME culture in general. This impacts education expectations and goals. On the other hand, ME culture is high in group collectivism valuing rewards in institutions, as well as loyalty towards families and organizations. An orientation towards people and group cohesiveness is strongly valued in the ME; whereas, in an Anglo culture, individualism and success may be more the focus. Furthermore, the Anglo cluster in general had a higher rating for future orientation and the $\mathrm{ME}$ culture lower. So people from an Anglo background may have a tendency to plan more systematically or be more motivated by future goals according to their cultural expectations, while in a Middle-Eastern setting, people may have learned to be more opportunistic, flexible, and adaptable. This was also reflected in a notable difference in scores in the 
category of uncertainty avoidance. Anglo cultures like Western Canada scored high for avoiding uncertainty, while the ME cultural cluster including Qatar scored lower, therefore, more comfortable with uncertainty. These cultural differences are expressed in the country, the institutions, and the classroom, and are therefore important to consider in transnational education. For the purpose of this research project, it is notable that the instructors and students in the Canadian University of Calgary in Qatar are from predominantly contrasting cultural groups.

These are cultural generalizations. A more detailed analysis of various cultures, characteristics and ratings may be found in the Global Leadership and Organizational Behavior Effectiveness study (GLOBE) [10]. This intensive global research study was conducted by 170 researchers over 10 years to note different cultural values, practices, and attributes.

\section{Research Project}

The research project was funded by Qatar National Research Foundation in order to investigate the learning styles and strategies of students in Qatar. This would benefit both students and educators to maximize academic efficacy.

The purpose of the project was twofold: first to research the learning styles field and select appropriate learning styles assessments for the context of students in Qatar; second to develop undergraduate students' research skills. The research project determined the learning styles of UCQ students and faculty as an initial study to benefit students and educators in general. The knowledge gained from this research helps inform teaching practices in Qatar by focusing on culturally appropriate pedagogy to benefit students in their preferred learning styles for their academic success.

The research entitled "International learning styles of post-secondary students in Qatar" was conducted and analyzed as a pilot project in the University of Calgary in Qatar by two Canadian faculty researchers and four Middle-Eastern undergraduate research students. They investigated the research literature in learning styles, strategies, cognitive processes, theoretical models, and testing methods. Then they applied two international learning style assessments and a set of background and interview questions to the majority of the Middle-Eastern students and Canadian faculty at the University of Calgary in Qatar. They discovered differences in attitudes towards education, and different learning styles and strategies between the instructors and the students, as well as among the students in different years of study at the university.

\section{Research Methods}

Two international learning style assessments were selected based on their suitability to the program and culture of the students, their cross-cultural application, and their being reviewed critically in the literature [5]. The Kolb learning style inventory (LSI) from America was chosen for its ease of use with EFL students, cross-cultural comparisons, widespread use in business and education at home and abroad, and several revised and updated models since 1976 [5,7]. The Vermunt inventory of learning styles (ILS) from Europe was selected to extend our understanding of students' strategies, motives and orientations towards learning. Vermunt was also quite favorably reviewed as one of the best models in terms of consistency and reliability in a 16 month "systematic and critical review of learning styles and pedagogy in post-16 learning” by Coffield, Moseley, Hall, and Ecclestone in 2004[5]. The Kolb LSI was also selected in this review as one of the most influential models.

In order to complement the learning style assessments, two questionnaires were devised. One asked for background information on the participants to determine characteristics associated with influencing learning styles such as age, gender, education background, work experience and culture. The second set of questions were open ended and formed the basis for an interview, so that researchers could find more personal and in-depth information about the students' views of learning.

A sample size of between $70 \%$ and $80 \%$ of students and faculty was determined as optimal and realistic. In order to achieve this, faculty and student researchers continued to run workshops until the target sample size was attained. The inventories and questionnaires were used in all workshops to assess the learning styles and attitudes of graduating students, continuing students, new students, and faculty in the spring and fall semesters of 2010. The research team categorized and analyzed the data with the aid of the Statistical Package for the Social Sciences (SPSS) program, and reviewed their research findings in 2011.

\subsection{Research Process}

The research process in this study was guided by the funding agency and the faculty researchers. The funding model for this project was designed to develop capacity amongst students who would eventually graduate and become part of the research 
culture in Qatar. This suggested we needed to develop or adopt a research model that included students as co-researchers in a thoughtful and sustainable manner. Subsequently a collaborative research model was developed, initially piloted during this research project, where all researchers (student and faculty researchers) worked in a safe, supportive and mentored environment. A guided inquiry process model was used to provide structure to the research project and to provide a process model that students could use throughout and after the project.

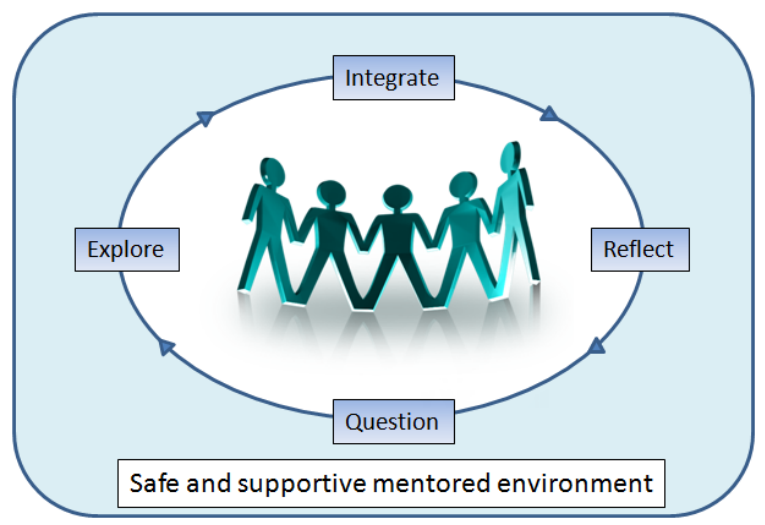

Figure 1: Collaborative research model

As a first step in the research process the team identified a number of questions that needed to be answered in order to get at the primary question. These formed the basis for an extensive literature review:

1. What are learning styles?

2. How are learning styles measured?

3. Are there cultural aspects involved?

4. What models are available?

5. Which would be appropriate for Qatar?

We searched and shared journal articles weekly for several months. We found that there are over 4000 professional publications referring to learning styles. There have been 70 to 100 learning style models developed. Learning style research and models span over 40 years [5]. Also, culture plays a major role in developing learning styles [19]. Currently, a dozen models are internationally used, extensively evaluated and critiqued [5]. From our literature review, we selected two international learning style assessment tools to be piloted on students in Qatar.

This collaborative process resulted in significant levels of engagement that were sustained throughout the project. Faculty and student researchers worked together through the process of literature review, ethics approval, workshops with learning style assessments and questionnaires, data analysis and dissemination. This research team approach and practical project helped generate detailed reports, several newspaper and magazine articles, conferences presentations and publications, and inquiries into extending the project to other institutions into 2012.

\section{Research Results}

The original hypothesis was that university and college students in Qatar from a Middle-Eastern educational and cultural background had unique ways of approaching their learning especially notable upon entry into a new Western system in their own country. This guided the research process and provided a framework for the researchers who also represented the ME students and the Western faculty. The end result of the research project and data analysis was that the majority of faculty and students' held different learning style preferences according to the Kolb LSI. The students' orientation towards education was further elicited in the Vermunt LSI reflecting cultural differences in their background education, current learning expectations, and career goals. Interviews also highlighted interesting attitudes of students about changes in their learning styles and strategies from their local high schools into the international post-secondary education system, and over the course of their studies at university. Students noted the impact of the instructors on their learning style and their motivation. Overall the research results highlighted these learning style differences between ME students and Western faculty in the Canadian University of Calgary in Qatar.

\subsection{Kolb Results}

The first international assessment tool used in this project is the Kolb Learning Style Inventory (LSI). It is a self-scored questionnaire which determines how the participant learns best in educational settings. The assessment consists of twelve questions and requires the user to rank order four responses where $1=$ most like you, $2=$ =more like you, $3=$ =less like you, and 4=least like you. The rank values for all questions are summed resulting in scores corresponding to four categories. The four categories of learning styles are: AC or Abstract Conceptualization, AE or Active Experimentation, RO or Reflective Observation, or CE or Concrete Experience [7] (see table 1). 


\section{Table 1: Description of Kolb’s learning styles}

\begin{tabular}{|l|l|}
\hline AE & $\begin{array}{l}\text { (doing) learn by actively experimenting, get } \\
\text { things done, take risks, influence others and } \\
\text { events through action }\end{array}$ \\
\hline AC & $\begin{array}{l}\text { (thinking) learn by abstract } \\
\text { conceptualization, think, analyze ideas } \\
\text { logically, plan systematically, understand } \\
\text { intellectually, develop theories }\end{array}$ \\
\hline RO & $\begin{array}{l}\text { (watching) learn by reflective observation, } \\
\text { watch carefully, see different perspectives, } \\
\text { look for meaning, gradually synthesize } \\
\text { conclusions }\end{array}$ \\
\hline CE & $\begin{array}{l}\text { (feeling) learn by concrete experience, relate } \\
\text { to people, be sensitive to feelings, personalize } \\
\text { learning, be involved }\end{array}$ \\
\hline
\end{tabular}

Typically respondents' results place them in one main category which indicates their strongest preference and their initial approach to a new learning situation. In some cases, respondents may exhibit a secondary preference nearly as strong as the first. This indicates a secondary style which may be preferred on occasion.

The participants, some $80 \%$ of students and the $90 \%$ of faculty, completed the Kolb LSI. The results from these inventories showed that the majority of the faculty preferred AC (Abstract Conceptualization) which could also be defined as thinking analytically, and planning systematically. Notably, faculty with a doctorate or with one in progress all had AC as their strength. On the other hand, the majority of the students preferred $\mathrm{AE}$ (Active Experimentation) or learning by doing, hands-on practice, and taking risks.

Closer inspection of the student results showed that there were also differences among the students depending on their year of study at the university. New students, for example, predominantly preferred AE or doing. Most second or third year students also preferred AE or doing, but Reflective Observation or watching as well. Graduating students had AC or thinking as their strongest category with $\mathrm{AE}$ or doing as their second strongest. Figure 2 shows the relative preferences of each learning style category depending on the type of student. Note roughly $10 \%$ of students in every year of study scored evenly across the four learning style categories, showing flexibility with using any learning style.

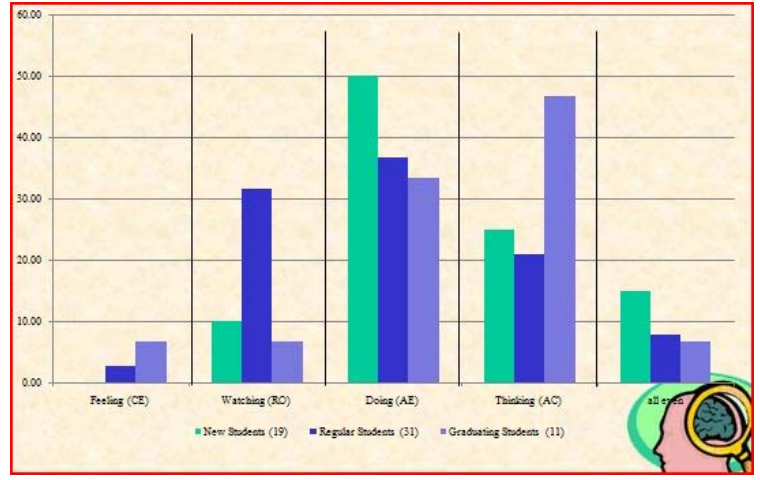

Figure 2: Kolb LSI results with \% of students with a dominant learning style.

Overall, Active Experimentation or a doing orientation for learning is preferred by all students. The graduating students also have as their strength Abstract Conceptualization or a thinking tendency towards learning. They were a unique cohort of post diploma nurses who had been in the University of Calgary in Qatar for three years to complete their studies to the degree level. Note that this AC category was also the preference of most of the Canadian faculty at this university.

When these differences are charted on a graph comparing students and faculty, a notable trend of opposite learning tendencies can be seen more clearly in figure 3. As is also seen in this figure, the four categories of the Kolb LSI represent two continuums. The first on the horizontal axis is the processing continuum, ranging from $\mathrm{AE}$ to $\mathrm{RO}$. The second on the vertical axis is the perception continuum, ranging from $\mathrm{CE}$ to AC.

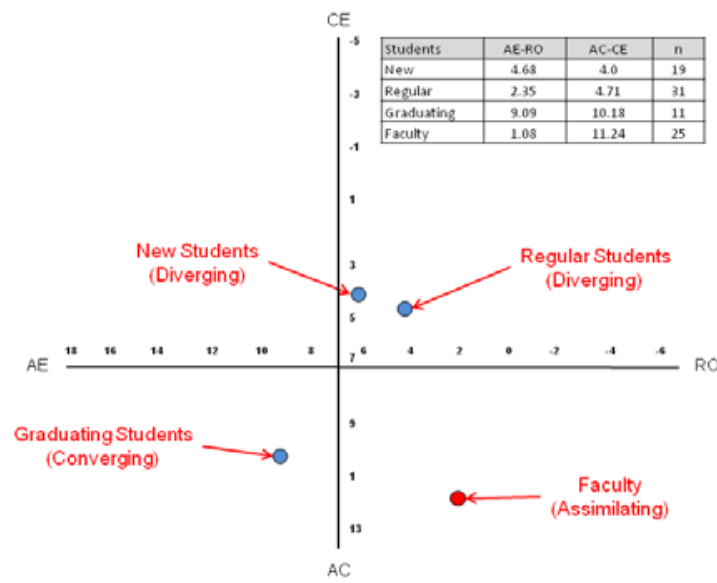

Figure 3: Student and faculty scores placed on the Kolb learning style quadrants.

The graph shows the combined strengths of the two continuums by using the scores of all the 
learning style categories as seen in the small table imbedded in the chart. These quadrants were different for faculty and students. The average of all faculty was Assimilating, and the average of all students was Diverging. In general students in the Diverging quadrant prefer concrete situations, observations, different viewpoints, brainstorming, broad interests, and gathering information and feedback, as well as working in groups. On the other side in the Assimilating quadrant, faculty like to gather lots of information in order to synthesize it into concise logical form, to think things through, and consider abstract ideas and concepts. Then they tend to present theories and models in lecture form.

Note also that the new students were closer to the borderline of the Accommodating quadrant. In the Accommodating quadrant, people prefer hands-on tasks, new experiences, carrying out plans, acting on intuition, solving problems, and field work.

Again the graduating students were slightly different as they placed on average in the Converging quadrant. In the Converging quadrant, these students prefer practical uses for ideas. They like to solve problems and make decisions. They tend towards technical tasks, new ideas, labs, and practical applications. This suits their nursing career.

\subsection{Vermunt Results}

The second international assessment tool used in this project is theVermunt Inventory of Learning Styles. It consists of four dimensions: (1) Processing Strategies, (2) Regulation Strategies, (3) Learning Orientations, and (4) Mental Models of Learning. It contains 25 Likert-style items for each of the dimensions resulting in a total of 100 questions.

Most of the students who completed the Kolb LSI in a workshop also completed the Vermunt ILS. This represented approximately 50\% of the UCQ student population at the time.

The results were collated and categorized by program year similar to the Kolb results (see table 2).

Table 2: Average ILS Scores by Program Year

\begin{tabular}{|c|c|c|c|}
\hline & $\begin{array}{l}\text { First } \\
\text { Year }\end{array}$ & $\begin{array}{c}\text { Second } \\
\text { to } \\
\text { Third }\end{array}$ & Graduating \\
\hline $\begin{array}{l}\text { Processing } \\
\text { Strategies }\end{array}$ & \multicolumn{3}{|c|}{$\begin{array}{c}1=\text { never, } 3=\text { regularly, } \\
5=\text { always }\end{array}$} \\
\hline $\begin{array}{ll}- & \text { Deep } \\
& \text { Processing } \\
\end{array}$ & 3.17 & 2.89 & 3.52 \\
\hline $\begin{array}{ll}- & \text { Stepwise } \\
& \text { Processing } \\
\end{array}$ & 3.71 & 3.49 & 3.64 \\
\hline $\begin{array}{ll}- & \text { Concrete } \\
& \text { Processing } \\
\end{array}$ & 3.02 & 2.67 & 3.58 \\
\hline
\end{tabular}

\begin{tabular}{|c|c|c|c|}
\hline $\begin{array}{l}\text { Regulation } \\
\text { Strategies }\end{array}$ & \multicolumn{3}{|c|}{$\begin{array}{c}\text { 1=never, } 3=\text { regularly, } \\
5=\text { always }\end{array}$} \\
\hline $\begin{array}{ll} & \text { Self } \\
& \text { Regulation }\end{array}$ & 3.34 & 2.97 & 3.64 \\
\hline $\begin{array}{ll}- & \text { External } \\
& \text { Regulation }\end{array}$ & 3.80 & 3.69 & 3.60 \\
\hline $\begin{array}{ll}- & \text { Lack of } \\
& \text { Regulation } \\
\end{array}$ & 2.47 & 2.51 & 1.50 \\
\hline $\begin{array}{l}\text { Learning } \\
\text { Orientations }\end{array}$ & \multicolumn{3}{|c|}{$\begin{array}{c}1=\text { disagree entirely, } 5=\text { agree } \\
\text { entirely }\end{array}$} \\
\hline $\begin{array}{ll} & \text { Personally } \\
& \text { Interested }\end{array}$ & 3.00 & 2.90 & 3.33 \\
\hline $\begin{array}{ll}- & \text { Certificate } \\
& \text { Directed } \\
\end{array}$ & 3.26 & 3.02 & 2.83 \\
\hline $\begin{array}{ll} & \text { Self-test } \\
& \text { Directed } \\
\end{array}$ & 3.73 & 3.32 & 3.22 \\
\hline $\begin{array}{l}\text { Vocation } \\
\text { Directed }\end{array}$ & 3.54 & 3.51 & 3.78 \\
\hline - $\quad$ Ambivalent & 2.48 & 2.53 & 1.75 \\
\hline Mental Models & \multicolumn{3}{|c|}{$\begin{array}{l}1=\text { disagree entirely, } 5=\text { agree } \\
\text { entirely }\end{array}$} \\
\hline $\begin{array}{ll}- & \text { Construction } \\
\text { of Knowledge }\end{array}$ & 3.18 & 2.93 & 3.69 \\
\hline $\begin{array}{ll} & \text { Intake of } \\
\text { Knowledge }\end{array}$ & 3.27 & 3.26 & 3.31 \\
\hline $\begin{array}{l}\text { - Use of } \\
\text { Knowledge }\end{array}$ & 3.31 & 3.37 & 3.81 \\
\hline $\begin{array}{ll}\text { - } & \text { Stimulating } \\
& \text { Education } \\
\end{array}$ & 3.27 & 3.20 & 3.50 \\
\hline - $\quad$ Cooperation & 2.98 & 2.88 & 2.67 \\
\hline
\end{tabular}

Note that even small differences denote trends for using a certain strategy over another, as the score is an average of all the student participants.

In the processing strategies the highest average for all students was for the category of processing material stepwise for memorization. However, the graduating students, compared to other students, scored higher in deep processing as well. They also scored higher than the others in the concrete processing of material for its use.

The regulation strategies section revealed a high score for self regulation of the process and result, combined with a high score for the results being externally regulated (by the teacher or university for example). The lowest score was in the category of 
lack of regulation which conversely meant that most students had a strong sense of control or regulation of their learning.

For the domain of learning motives or orientations, the highest scores were for vocation and self-test reasons for studying. The lowest score for an ambivalent motivation conversely meant that UCQ students were not ambivalent; they knew why they were studying at the university. This stands to reason, as the university is specialized for a bachelor's degree in nursing.

As for the final domain of mental modes of learning or views of studying, the highest average was to make use of the knowledge. Students also averaged a high score for taking in knowledge and expecting education to be stimulating (by the teacher).

Overall the Vermunt ILS showed that on average students tended towards stepwise and concrete processing of material and less deep processing such as critical thinking until their graduating year. Students felt that they controlled or regulated the process and results of the course, as well as the teacher. Their learning motive or orientation, on average, was for self-testing and for their vocation. They made use of knowledge in a course, and expected teachers to make education a stimulating experience.

\subsection{Interview Results}

After the two learning styles test instruments, several students were selected for an interview to discover more reasons for their strategies in an openended style of questioning. This accounted for about $20 \%$ of the student population at UCQ. Researchers asked five questions to discover students' personal viewpoints.

These were the questions:

1. During the workshop with tests on learning styles, what did you learn or find interesting about your learning style?

2. How do you study, do well on assignments or prepare for tests?

3. Do you think your culture or background experience affect your way of learning? Explain.

4. Has your learning style changed from high school or during your studies at UCQ? How? Do you think teachers affect your style?

5. Is there anything else you would like to share about your learning experience?
Student responses were insightful because they represented more personalized subjective viewpoints, and expressed their attitude towards their learning styles. For example, the first question asked students to reflect on their learning styles workshop experience.

"This is [the] first time...I found it interesting to know my learning style which is doing."

"I found that I learn through watching, listening and practicing."

"The result of the test is right."

"I love it a lot."

"I learn how... to study for my test."

"I learn that my learning style is different from high school."

"I learn about my way of learning and I found it nice."

"When I discovered I'm learning using my feeling, it was a great experience."

"I wasn't surprised...because I knew I used to think before [I] act."

"I loved to know my learning style."

"To know what is my style was the interesting part.”

Students' responses varied. Overall, students found the learning styles workshops interesting and informative. Some also expressed their positive feelings around the discovery of their learning style.

For the second question about how students study and prepare for tests, the responses revealed a variety of techniques.

"I study the handouts and my notes that I wrote in the class."

"I do first brain storm and then solve my assignments."

"Review what I took in the class and study from the book."

"First I read the part I want to study then write it in a paper. Also, sometimes I draw for myself to understand better."

"Do example for myself and try to test myself."

"I study by exercising."

"I prepare and study directly after I take the class.”

"I read and understand the things I'm reading. Most of the time I like to see and explain for myself."

"I look for some website and collect the information and write it down in my words. For tests I read the books."

"I didn't do much preparation for exams but I mostly depend on class work and lectures.” 
"I study in the beginning of the semester and try to get things on time, so before the exam night, I get to review."

"I have many ways for each type of assignment."

Overall, students reflected more on their habits. It was interesting to note the different ways that they prepared for classes, assignments and tests. Some relied more exclusively on the teacher, but most tried to practice and review after class.

The third question was about whether or not culture or background experience affected their way of learning. From 13 interviews, 6 students said "no", 6 students said "yes”, and 1 was "not sure”.

“Well I'm not quite sure, but I don't think so, there is any affects. However, our culture nowadays is improving and gives us opportunity to educate ourselves."

"No, there is no relationship between them, because my way of learning is in me from the day I [was] born.”

"Yes, my culture asks us to educate ourselves. My whole family [are] educators and they support me to study."

Due to the types of responses and the brevity, perhaps this question was not clear to students. They may not be totally aware of how culture influences them or their instructors or how it impacts the educational setting.

The fourth question asked students to reflect on the transition from high-school, as well as on the university teachers' influence on their way of learning. This time students responded more emphatically and individually.

"Yes, the way of study had been changed."

"Teachers encourage me to study by giving assignments."

"Teachers helped me a lot by giving me effective ways to study."

"In high school I only remember the subject... However, in UCQ I need to understand the subject and I always ask my teacher to help me and to explain for me. The teacher affect on my style, because their style is different from my learning style. Also, if the teacher is nice I will study well and will love the class, but if she is not I will not study well."

"Also I need to see more than one source to help me out to understand well. The teachers affect me a lot, because their way is completely different from us as students."

"Yes, my learning style changed from high school and now I have more experience. They affect a lot, because they teach us in many different ways of learning that help us."

"I need to understand and do more research for assignments.”

"Yes of course it changed, because in high school I always study what my teacher gives me. But here I do research and a lot of writing by myself."

"In high school we were memorizing materials, but since I became a student in Calgary, I learn better from what teachers say during class... I just read power points and the course books for the exams."

"I improved a lot since I came at UCQ."

This question revealed that the students noticed a major transition from high school to university. In this particular setting, most students had moved from a predominantly Middle-Eastern high school system to a Canadian university in Qatar. Thus it is interesting to note their awareness of this change and their growing maturity to respond to it.

For the last question, students were given the option to share more or conclude the interview. Half of the students chose to add no more. The other half tended to thank the interviewer and wish us luck.

"I’m happy to be part of your project interview. Good luck to all of you in this project.”

"Thanks for letting me know what is my learning style."

"I will be looking forward [to] the result."

"It was a great experience that gave me the chance to know more about my learning style.”

The student's perceptions were valuable as they became more aware of their learning style and the teachers' styles, and the contrast between high school and university. Also these more subjective reflections and responses complement the more measured questions of the learning style inventories of Kolb and Vermunt.

\section{Discussion}

The tests and interviews highlighted some interesting differences among the students, and the Kolb LSI in particular brought out the differences in learning style preferences between the faculty and the students at UCQ. Faculty were predominantly educated to university level in North America and acculturated to the Anglo system. This contrasts with the Middle Eastern culture cluster of the students and their education in the secondary school system in Arabic as the first language and English as a foreign one. These cultural backgrounds tend to influence learning style preferences and orientations [19]. It was notable that learning style preferences changed 
over the course of the students' studies shifting from a doing to a more experimental and thoughtful style.

Perhaps, influences such as educational background and context were affecting students as they proceeded through their university degree. Most students upon entering the university had a "doing" learning orientation; whereas, more graduating students exiting had a thinking orientation. This could be because North American universities like UCQ emphasize critical awareness and thinking in their courses. They tend towards an inquiry approach to learning. The emphasis is also on theories and abstract conceptualization, as well as evidence based practice. Over time (several years) students may adapt their learning to this context or to the faculty style which was also a predominantly thinking orientation. The faculty results too could be explained by their higher degrees in a North American university setting which influences their approach and review of information in this manner. Even so, the learning style preferences of the graduating students were at some distance from those of faculty, because in the end they preferred both thinking and doing.

Kolb also emphasizes that in a well rounded learning process, learners would cycle through the four phases. So students may prefer to start with Active Experimentation, but it would be best if they could continue with Concrete Experience to personalize the activity, and then Reflective Observation to see different perspectives, and also to move on to Abstract Conceptualization to think things through, and finally perhaps combine ideas into a theory, before putting it into practice again. So over time, students at UCQ possibly adapted from their doing orientation in the first year, to reflection in the second, and in the final year to thinking, but were still always strongly drawn towards their preference to practice. The faculty style and the university setting also probably caused them to move more towards critical analysis.

The Vermunt ILS further indicated that the students were very practically oriented. Overall, they wanted to take in and test their knowledge, and have useful, concrete courses for their vocation. This is consistent with being a nurse and reflected the pragmatic nature of their career choice.

The interviews indicated that the students became more aware of their learning styles and strategies. They also recognized the influence of the university and the instructors on their way of learning and even their motivation. In general, they realized that they needed to understand the material more in depth, and do more independent studying and research for their program at the university.
The results were notable for this university especially for the instructors and students to gain a greater awareness of differences in learning styles and culture.

However, this initial research project was a pilot study on one university population in Qatar. Therefore, the extension or applicability of the results to other higher institutes of education is limited or speculative. Still UCQ has a diversity of students from the Middle East, and a faculty from the West, so the contrasting learning style results are informative both from a cultural point of view, and from an educator's viewpoint. Further research is required at other post-secondary institutions to generalize the results in the region as well as to compare it with international studies.

\section{Conclusion}

Awareness of different approaches to learning and expectations for the learning environment are crucial in a transnational institution. Although limited in scope to the Canadian University of Calgary in Qatar, this research study provided an insightful snapshot of different learning styles and study preferences of students in various years of study at the university. Also the distance between faculty and students' learning styles in any year of study was notable. This is more compelling as it represented the differences between western faculty and ME students and could be linked to cultural differences as well. An awareness of these findings can help the institution adapt and grow, as well as help students and faculty better understand their relative starting points when working together.

The project was also useful and interesting from the point of view of both students and faculty at UCQ. The Kolb assessment showed that UCQ faculty tended towards abstract conceptualization or the thinking process; whereas most students preferred active experimentation or doing tasks. In general, according to experiential learning theory, it is natural and easier for a learner to start with his particular learning style strength such as doing a task, and then move into the other modes of learning, such as having a personal experience or reflectively watching a model demonstration, or critically analyzing the results or mistakes. So, as the cycle of learning for Kolb's model suggests, perhaps instructors could initially use more practical and concrete tasks for students, and then guide them into more critical reflection and thinking. Furthermore, the Vermunt ILS outcomes also suggest that students prefer concrete and useful knowledge, and that they prefer step by step processing. Teachers are expected by these students to guide them, and also make the 
learning environment more concrete and stimulating. Finally, according to the interviews, students noted that in their cultural context, instructors influence their learning greatly and the students depend more on the teachers' input and support.

The findings of this project also suggested that students may change as they move through the educational program showing a willingness and capacity to adapt. Although this study did not have a large enough faculty sample to see similar patterns, it may be that faculty adapt as they gain experience working in a transnational setting.

In transnational institutions or in learning environments where instructors and students differ in education and cultural backgrounds, an awareness of differences in values, learning styles, attitudes, and strategies may be helpful to more effectively bridge the education gap. As the number of transnational branch campuses increase, the need to understand the cultural differences that impact teaching and learning become of paramount importance. The success of these programs may depend on understanding and addressing these differences in culture and education.

\section{Acknowledgement}

UCQ is thankful for the support of Qatar National Research Fund of Qatar Foundation for the Undergraduate Research Experience Program. Students engage in significant research projects to benefit Qatar. The faculty researchers are also grateful for the support of the UCQ research team, and the University of Calgary in Canada.

\section{References}

[1] A. Gopal, "Internationalization of higher education: Preparing faculty to teach cross-culturally”, International Journal of Teaching and Learning in Higher Education, 23(3), 2011, pp. 373-381.

[2] A.B. Cohen, "Many forms of culture", American Psychologist, 64(3), 2009, pp. 194-204.

[3] C. Miller-Idriss and E. Hanauer, "Transnational higher education: Offshore campuses in the Middle East", Comparative Education, 47(2), 2011, pp. 181-207.

[4] Cassidy, S., Learning Styles : An overview of theories, models, and measures. Educational Psychology, 24(4), 2004, pp.419-444.

[5] Coffield, F.J., Moseley, D.V., Hall, E., and Ecclestone, $\mathrm{K}$., Learning styles and pedagogy in post-16 learning: a systematic and critical review, Learning and Skills Research Centre, London, UK, 2004.
[6] Felder, R. M., Learning and teaching styles in foreign and second language education. Foreign Language Annals, 28 (1), 1995, pp.21-31.

[7] Kolb, D.A., Experiential learning: experience as the source of learning and development, Prentice Hall, Englewood Cliffs, NJ, USA, 1984.

[8] Kolb, D. A. and Kolb, A. Y., "Learning styles and learning spaces: enhancing experiential learning in higher education", Academy of Management Learning \& Education, 4(2), 2005, pp.193-212.

[9] Gardner, H., Intelligence Reframed: Multiple Intelligences for the $21^{\text {st }}$ Century. Basic Books, NY, USA, 1999.

[10] Globe. "Global Leadership and Organizational Behavior Effectiveness Research Project”, Retrieved from http://www.thunderbird.edu/sites/globe/, Glendale, AZ, USA, 2011.

[11] Hofstede, G., Culture's consequences, Sage, Newbury Park, CA, 1984.

[12] House, R.J., Hanges, P.J., Javidan, M., Dorfman, P.W., and Gupta, V. Culture, Leadership, and Organisations. Sage, Thousand Oaks, CA, USA, 2004.

[13] J.D. Vermunt, "Relations between student learning patterns and personal and contextual factors and academic performance”, Higher Education, 49, 2005, pp. 205-234.

[14] J.D. Vermunt and Y.J. Vermetten, "Patterns in student learning: relationships between learning strategies, conceptions of learning, and learning orientations", Educational Psychology Review, 16(4), 2004, pp.359-384.

[15] Langton, N. \& Robbins, S.P., Multiple pathways to learning: Organizational behavior: Concepts, controversies, applications (4 $4^{\text {th }}$ ed.). Toronto: Pearson Education Canada, 2007.

[16] Northouse, P.G., Leadership theory and practice $\left(4^{\text {th }}\right.$ ed.). London, UK: Sage Publications, 2006.

17. Peterson, B., Cultural Intelligence. Boston, USA: Intercultural Press, 2004.

[17] Rayner, S. \& Riding, R., Towards a categorisation of cognitive styles and learning styles. Educational Psychology, 17 (1/2), 1997.

[18] S. Joy and D.A. Kolb, "Are there cultural differences in learning style", International Journal of Cultural Relations, 33(1), 2009, pp. 69-85.

[19] Smith, J., Learning styles: fashion fad or lever for change? The application of learning style theory to inclusive curriculum delivery. Innovations in Education and Teaching International, 39(1), 2002, 63-70. 